\title{
Propriedade e apropriação em Hannah Arendt
}

\section{Propriety and Appropriation in Hannah Arendt}

DOI: $10.20873 / \mathrm{rpv} 6 \mathrm{n} 2-08$

\section{Cícero Oliveira}

Orcid: 0000-0002-4517-8510

Email: cicerojosinaldo@ufg.br

\begin{abstract}
Resumo
O pensamento político de Hannah Arendt é marcado por uma rigorosa distinção entre as esferas privada e pública das relações. Não obstante, Arendt sustenta uma feição não privativa da vida privada especialmente ligada ao sentido político da propriedade. Em seu diagnóstico crítico acerca da modernidade, presente em $A$ condição humana, ela sustenta que a dissolução desse vínculo fundamental, a compreensão moderna da política como uma sociedade de proprietários (liberalismo) e a conversão da riqueza em preocupação coletiva compõem o quadro de uma "humanidade socializada", isto é, de sociedades enredadas à vida em sua dimensão elementar ou biológica em detrimento da mundanidade e da política.
\end{abstract}

\section{Palavras-chave}

Propriedade, apropriação, vida, mundanidade.

\begin{abstract}
Hannah Arendt's political thought is marked by a rigorous distinction between the private and public spheres of relations. Nevertheless, Arendt sustains a non-private feature of private life, especially linked to the political sense of property. In her critical diagnosis of modernity, present in The Human Condition, she argues that the dissolution of this fundamental link, the modern understanding of politics as a proprietary society (liberalism) and the conversion of wealth into collective concern make up the framework of a "socialized humanity", that is, of societies entangled in life in its elementary or biological dimension to the detriment of worldliness and politics.
\end{abstract}

\section{Keywords}

Property, appropriation, life, worldliness. 
O diagnóstico geral de $A$ condição humana encontra sua mais concisa e abrangente formulação no que Arendt chama de a vitória do animal laborans ou a vitória da sociedade de consumidores. Esta sociedade "não surgiu em decorrência da emancipação das classes trabalhadoras, mas resultou da emancipação da própria atividade do trabalho, séculos antes da emancipação política dos trabalhadores" (ARENDT, 2010, p. 156-157). Ao sustentar que o processo biológico da vida estabeleceu seu próprio domínio público no qual os homens aparecem não tanto como agentes, mas antes como viventes, a noção arendtiana de "domínio social", implica a compreensão de que não é indiferente o lugar em que as atividades humanas fundamentais sejam exercidas e que o caráter da esfera pública corresponde ao das atividades que nela são admitidas.

O animal laborans como o tipo humano vencedor na modernidade, uma figura histórica de tendência hegemônica e desarticuladora da vida ativa (trabalho, obra, ação), um espírito de época e não mais o representante de uma condição incontornável da condição humana, resulta, a crermos nas análises de Arendt, numa progressiva implicação do biológico tanto sobre o poder político, quanto sobre os limites que separa a vida elementar de todo o artifício humano que ela conceitua como o mundo. De um modo geral, a vitória do trabalho ou a moderna abrangência de seu domínio, corresponde ao fato de que o imperativo da necessidade a ele inerente, suas relações organizacionais e o princípio da efemeridade que governa sua temporalidade curta terminam por alterar o propósito e a natureza da esfera pública (de espaço da liberdade em organização coletiva do processo vital) e a minar a durabilidade do mundo.

De acordo com Arendt, existe no limiar da modernidade um evento que foi particularmente decisivo na constelação da vida ativa com que a era moderna promoveu o trabalho, a mentalidade consumidora e seu modo correlato de lidar com os assuntos humanos (a política) e universo das coisas (o mundo). Trata-se da Reforma Protestante que ao promover a expropriação liberou dos campos os trabalhadores incorporados às linhas de produção industrial, possibilitando uma nova escala do acúmulo de riqueza social. 0 decisivo é que, na contramão 
da tradição antiga que concebeu a propriedade privada em sua significação política, porque em conexão com o mundo humano, a modernidade foi deflagrada justamente pelo fenômeno expropriação ${ }^{1}$.

Somente com o aparecimento desse mundo comum em uma tangibilidade concreta, isto é, com o surgimento da cidade-Estado, pôde esse tipo de propriedade privada adquirir sua eminente significação política. Portanto é um tanto natural que o famoso "desdém pelas ocupações servis" não seja ainda encontrado no mundo homérico. Caso o dono de uma propriedade preferisse ampliá-la ao invés de utilizá-la para viver uma vida política, era como se ele sacrificasse prontamente a sua liberdade e voluntariamente se tornasse aquilo que o escravo era contra sua vontade, ou seja, um servo da necessidade. [...] Devemos o pleno desenvolvimento da vida no lar e na família como espaço interior e privado ao extraordinário senso político do povo romano, que, ao contrário dos gregos, jamais sacrificou o privado ao público, mas, ao contrário, compreendeu que esses dois domínios somente podiam subsistir sob a forma da coexistência. (ARENDT, 2010, p. 80, 64)

Com base nas obras de Fustel de Coulanges, R. H. Barrow, J. Ashley, Karl Kerenyi e Levasseur, Arendt argumenta que a despeito de todas as reservas, em seu nível mais elementar, a dimensão não privativa da esfera privada antes da era moderna se manifestava, tanto para os antigos quanto para os medievais, na questão da propriedade privada. A conexão básica entre privado e público, indicada pela feição não privativa da vida privada, devia-se à compreensão de que a propriedade que os indivíduos possuem privadamente, o lar, corresponde aos seus respectivos lugares no mundo a partir dos quais chefiam as famílias cujo conjunto forma o mundo comum em que eles tomam parte.

Segundo Arendt, o mais claro sinal de que a propriedade era antes de tudo uma referência ao lugar que o indivíduo ocupa no mundo, e, portanto, a condição elementar e pré-política da cidadania, é dado tanto pelo fato de que "a expulsão de um cidadão podia significar não apenas o confisco de sua propriedade, mas a efetiva destruição de sua própria morada", como

\footnotetext{
1 "A reforma contribuiu, em um aspecto específico, para que o processo de alienação do mundo fosse o eixo de sustentação da história moderna. A expropriação dos bens eclesiásticos ocorrida naquele momento levou ao empobrecimento de uma enorme massa de camponeses, deixados à míngua em uma situação em que, destituídos de um lugar no mundo, ficaram expostos, de mãos vazias, às conjunturas da vida, tendo apenas sua força de trabalho para vender. Essa massa serviu de mão de obra para impulsionar a Revolução industrial, na Inglaterra e no restante da Europa, e foi abrigada, de forma mais ou menos precária, nas sociedades europeias até o século XX" (JARDIM, 2007, p. 35).
} 
também porque "a riqueza de um estrangeiro ou de um escravo não substituía, em nenhuma circunstância, essa propriedade" (ARENDT, 2010, 75, 76).

Antes da modernidade todas as civilizações, a despeito das reservas com o que nela há privativo, admitiram o valor político da esfera privada. Essa feição não privativa se baseava na compreensão de que da esfera privada decorrem as condições para o interesse pelos assuntos públicos; os assuntos em que os membros de uma determinada comunidade estão concernidos.

De fato, para Arendt a mundanidade relacional, isto é, o envolvimento humano com as coisas do mundo, supõe a propriedade em seu sentido político-mundano tal como os antigos souberam desvelar. Daí que os modernos defensores da propriedade privada, que a identificam exclusivamente com a apropriação, com um processo ilimitado de aquisição e acúmulo de riqueza, não têm motivos para recorrer à tradição greco-romana. Que o processo moderno de apropriação remonte ao esbulho das classes camponesas é fundamental para reconhecermos que "o dito de Proudhon - de que a propriedade é um roubo - tem sólida base de verdade nas origens do moderno capitalismo" (ARENDT, 2010, p. 82).

Ao reconhecer que "a propriedade, distintamente da riqueza e da apropriação, indica a parte de um mundo comum que tem um dono privado e é, portanto, a mais elementar condição política para a mundanidade do homem", Arendt identificou o moderno expediente da desapropriação de certas camadas da população e o processo ainda em curso de enriquecimento que este evento deflagra, como parte do fenômeno moderno de alienação do mundo, isto é, com "o despojamento de certos grupos do seu lugar no mundo e sua nua exposição às exigências da vida" (ARENDT, 2010, p. 315, 317).

Constrangida aos cuidados elementares de si, alienada de qualquer outra forma de preocupação que não decorresse das demandas vitais, a nova classe trabalhadora foi levada a liberar no mundo "a energia inerente à 'força de trabalho', à mera abundância natural do processo biológico que, como todas as forças naturais - da procriação tanto quanto da atividade do trabalho -, garante um generoso excedente muito além do necessário à reprodução de jovens para contrabalançar os velhos" (ARENDT, 2010, p. 318). 
Em consequência, submetida à interminabilidade do processo produtivo de ritmo industrial, a fabricação (não obstante a durabilidade potencial de seus produtos) se tornou o testemunho de que a implicação fundamental da liberação da força de trabalho deriva do fato de não se restringir às classes expropriadas e mais imediatamente absorvidas pelos processos de trabalho. Pois tanto para os trabalhadores quanto para os investidores da nova indústria, o determinante era a adstrição a processos de ciclos metabólicos. Os primeiros porque constrangidos pelas carências vitais, os segundos enquanto mobilizados pelos lucros e pela apropriação crescente, para o que era necessário a dinâmica característica que a operacionalidade do sistema capitalista veio inaugurar: realimentar o processo para gerar novas expropriações, maior produtividade e mais apropriação².

Daí que, enquanto processo natural, a força de trabalho tenha ultrapassado os limites das classes expropriadas e se disseminado a toda sociedade por meio do acúmulo de capital, um processo crescente e infindável de apropriação. Em todo caso, a apropriação permanece sempre tributária de seu evento desencadeador, pois "o processo de acúmulo de riqueza, tal como o conhecemos, estimulado pelo processo vital e, por sua vez, estimulando a vida humana, é possível somente se o mundo e a própria mundanidade do homem forem sacrificados" (ARENDT, 2010, p. 318-319). Deflagrada pela expropriação, essa forma de a alienação do mundo segue em parte com o processo econômico de crescimento da riqueza alçado à principal preocupação coletiva ${ }^{3}$. Em face das transformações modernas operadas na esfera política

\footnotetext{
2 “A Revolução Industrial se fez possível pela exploração e proletarização; isto é, pelo desarraigamento e pelo fato de que muitos homens se tornaram supérfluos. No lugar da propriedade, que assinalava ao homem seu lugar no mundo, se introduziu o posto de trabalho e o puro funcionar no processo de trabalho" (ARENDT apud DUARTE 2010, p. 315).

3 'Uma vez que o capitalismo não dava sinais de desagregação 'sob o peso das suas contradições econômicas' [Marx], Rosa Luxemburgo procurou uma causa externa que explicasse a sua subsistência e o seu crescimento. Recontou-a na chamada teoria do terceiro homem, ou seja, no facto de o processo de crescimento não ser simples consequência das leis inatas a que obedeceria a produção capitalista, mas da subsistência, no campo, de sectores pré-capitalistas que o 'capitalismo' ia captando e atraindo para a sua esfera de influência. Depois de este processo alastrar a todo o território nacional, os capitalistas viam-se obrigados a dirigir as atenções para outras zonas do mundo, para os países, pré-capitalistas, e arrastá-las para o processo de acumulação de capital que, por assim dizer, se alimentaria de tudo quanto fosse exterior a si próprio. Por outras palavras, a 'acumulação primitiva do capital' de Marx não era, ao contrário do pecado original, um facto isolado, um ato único de expropriação por parte da burguesia nascente, desencadeando um processo de acumulação que a partir daí obedeceria 'com necessidade férrea' à sua própria lei até a desagregação final. Muito pelo contrário, a expropriação tinha que se repetir constantemente para manter o sistema em funcionamento. 0 capitalismo não era, por conseguinte, um sistema fechado
} 
podemos dizer que "a socialização do homem é mais eficazmente realizada por meio da expropriação". (ARENDT, 2010, p. 88)

A preocupação "pública" com a riqueza é justamente o outro lado de uma humanidade inteiramente socializada; de uma sociedade da espécie humana unida unicamente em prol da sobrevivência e do que serve à sobrevivência. De modo geral, "a marca distintiva da moderna teoria política e econômica, na medida em que considera a propriedade privada como questão crucial, tem sido sua ênfase nas atividades privadas dos proprietários e em sua necessidade de proteção governamental para o acúmulo de riqueza, à custa da propriedade tangível" (ARENDT, 2010 , p. 83, 199). 0 interesse que une os homens em torno de um governo se refere às garantias de proteção relativas aos seus interesses privados de aquisição. Mas a contradição entre público e privado que os teóricos da política moderna, a maneira de Bodin, tentaram contornar, deixou de ser um problema para a teoria política moderna com a consolidação da esfera social, na qual as diferenças entre os domínios público e privado restam diluídas.

Concebida em vista do processo de apropriação, a concepção moderna de governo (o liberalismo) fez da riqueza comum, alçada à esfera pública, o substituto do mundo comum enquanto cenário destinado ao influxo humano. E essa organização social da espécie humana em torno das posses privadas em expansão também mina a durabilidade do mundo, porque a riqueza é transformada em capital e a propriedade em apropriação. Como o vínculo social em torno desse processo é incapaz de constituir um mundo comum e durável de coisas, o que realmente há de comum numa comunidade socializada, na qual a riqueza conquistou a esfera pública, é somente o governo pelo qual os cidadãos-proprietários firmam garantias mútuas.

0 que Arendt chama de "evaporação social do tangível" equivale à transformação da propriedade imóvel em propriedade móvel e registra a crescente perda do valor de uso privado

\footnotetext{
que gera as suas próprias contradições e está 'prenhe de revolução'; alimentava-se de factores externos, e a sua derrocada automática só poderia eventualmente verificar-se quando toda a superfície da terra tivesse sido conquistada e devorada" (ARENDT, 1991, p. 52-53).

Mais recentemente, Zygmunt Bauman levou esta tese adiante. Pensando a partir das contribuições de Rosa Luxemburgo ele afirma o seguinte: "sem meias palavras, o capitalismo é um sistema parasitário. Como todos os parasitas, pode prosperar durante certo período, desde que encontre um organismo ainda não explorado que lhe forneça alimento. Mas não pode fazer isso sem prejudicar o hospedeiro, destruindo assim, cedo ou tarde, as condições de sua prosperidade ou mesmo sua sobrevivência" (BAUMAN, 2010, p. 08-09. Ênfase do autor).
} 
em virtude da qual as coisas puderam receber um valor fundamentalmente social, determinado pela permutabilidade oscilante como ela se expressa na conexão com o denominador comum do dinheiro. Nas condições modernas de supremacia do valor social, os objetos estão mais suscetíveis à "evaporação social do tangível”, isto é, mais propícios a se prestarem à função de bens de consumo, que é a exigência operacional de base da obra submetida à interminabilidade do processo de trabalho. Para esse concorreu a mais revolucionária concepção moderna a respeito da propriedade, formulada por Locke. Aquela

Segundo a qual a propriedade não constituía uma parte fixa e firmemente localizada do mundo, adquirida por seu proprietário de uma maneira ou de outra, mas, ao contrário, tinha no próprio homem a sua origem, na sua posse de um corpo e na sua indiscutível propriedade da força desse corpo, que Marx chamou de "força de trabalho" [labor-power]. (ARENDT, 2010, p. 85).

Como sabemos, o que está em questão para Locke na análise do trabalho não é apenas o problema de assegurar a origem e o fundamento da propriedade privada, mas igualmente a legitimidade de sua ampliação ilimitada em porções desiguais; a apropriação processual nos moldes em que ela persiste em nosso tempo. Um aspecto fundamental da era moderna é que essa concepção lockeana tenha conceituado e sistematizado um processo cujos desdobramentos solaparam a antiga dimensão mundana da propriedade, independente dos meios pelos quais ela pudesse ter sido adquirida.

Com o Segundo tratado sobre o governo civil de John Locke emerge uma compreensão de homem marcadamente econômica: o proprietário de si mesmo, fonte de toda propriedade, cuja radicalização será a compreensão de homem como empresário de si, do neoliberalismo. Mas a razão pela qual o interesse moderno pela apropriação pôde encontrar guarida na posse incontestável que o homem tem de seu corpo - a partir daí identificado como fonte legítima de apropriação -, devemos ao fato de que a força que ele libera, a "força de trabalho", constitui um processo cujos limites (assim como os da possibilidade de apropriação) são dados apenas pelos dois eventos supremos do processo vital: nascimento e morte. Em todo caso, a morte individual não chega a ser um inconveniente à acumulação processual de riqueza para uma humanidade socializada organizada em torno da vida como evento biológico. 
Somente se a vida da sociedade como um todo, ao invés da vida limitada dos indivíduos, é considerada como o sujeito gigantesco do processo de acumulação, pode esse processo seguir totalmente livre e em plena velocidade, isento dos limites impostos pela duração da vida individual e pela propriedade possuída individualmente. Somente quando o homem deixa de agir como um indivíduo interessado apenas por sua própria sobrevivência, mas como um "membro da espécie", [...] somente quando a reprodução da vida individual é absorvida pelo processo vital da espécie humana, pode o processo vital coletivo de uma "humanidade socializada" seguir sua "necessidade", isto é, seguir o seu curso automático de fertilidade, no duplo sentido da multiplicação de vidas e da crescente abundância de bens exigida por elas. (ARENDT, 2010, p. 143)

O processo de acumulação de riqueza somente pode ser ilimitado quando se ultrapassa os limites individuais de apropriação. Ele se torna altamente acelerado quando o enriquecimento contínuo é o projeto coletivizado pelo qual a própria riqueza estável constituída de coisas armazenáveis e acumuláveis (Locke) é evaporada ou mudada no curso de um processo de liquefação (Bauman), de aquisição de dinheiro destinado ao gasto e ao consumo. Porque "já vivemos em uma sociedade em que a riqueza é aferida em termos da capacidade de ganhar e gastar, que são apenas modificações do duplo metabolismo do corpo humano" (ARENDT, 2010, p. 154).

A vitória do animal laborans sobre o homo faber é antes de tudo a vitória da vida sobre o mundo, do trabalho sobre a obra, do consumo sobre o uso. Mais do que um divórcio entre propriedade e mundanidade, isto é, o fim histórico da remota correlação entre a propriedade e uma parte fixa e durável do mundo, o que se nos depara, enquanto desdobramento do tipo de "propriedade" que a modernidade passou a aspirar, é que, com a viabilização da abundância pressuposta nos novos ideários de riqueza e crescimento, foram lançadas as bases a partir das quais se instituiu uma nova ordem econômica. Trata-se de uma economia inconciliável com a categoria de obra, guiada pela renovação, presidida pela temporalidade curta e pela repetição que são as marcas inconfundíveis do trabalho. Trata-se, enfim, da "lógica econômica que realmente varreu todo ideal de permanência, a regra do efêmero que governa a produção e o consumo de objetos" no horizonte de uma temporalidade curta (LIPOVETSKY, 2009, p. 185).

No cerne dessas transformações encontramos o incremento das forças produtivas como fenômeno que ajustou as condições de produção aos interesses burgueses relativos ao processo ilimitado de aquisição e acúmulo de riqueza. 0 ideal de riqueza em contínua expansão que 
norteou a modernidade alcançou as condições de sua realização na abundância ou na profusão sempre crescente de coisas que as novas capacidades técnicas, aliadas às transformações organizacionais das forças produtivas, proporcionaram.

É no processo de constituição do capitalismo industrial, deflagrado por uma revolução técnica sem precedentes, que encontramos a otimização das forças produtivas ajustadas aos princípios de repetição e interminabilidade; a conversão da fabricação em trabalho. Na base dessa conversão encontramos o fenômeno histórico da expropriação pelo qual as classes pobres foram constrangidas às carências vitais, liberando a fertilidade natural, a "força de trabalho" do organismo humano para fins de uma produtividade sem precedentes. Longe de ser um entre outros expedientes da era moderna, a expropriação lhe determina um traço característico, pois a condição de indigência a que submeteu as forças produtivas implica um modo de mobilização em si mesmo indicativo da intensidade e do ritmo produtivo que se pretendia inaugurar.

Mesmo que de modo paradoxal, na medida em que implicava a submissão da força de trabalho à situação de penúria, a expropriação foi o expediente não técnico de otimização das forças produtivas. Porque o vigor das forças agenciadas decorria justamente de suas necessidades imperiosas redobradas pelas condições sistemáticas de exploração que, no limite da própria vida, testou e levou ao limite a capacidade da força de trabalho ou das forças produtivas.

Agenciada pelas linhas de produção do capitalismo industrial, esta força de trabalho (que atende ao processo natural do metabolismo humano com a natureza e se caracteriza por uma fertilidade natural graças à qual o trabalho de alguns é o suficiente ao provimento das necessidades de muitos), nas condições de expropriação, respondeu mais em termos de produção de mercadorias do que em termos de reprodução do processo vital. Seu resultado foi a profusão, a produção pletórica de coisas e não propriamente a abundância dos bens necessários ao ciclo vital do organismo humano.

$\mathrm{Na}$ primeira fase do capitalismo industrial é especialmente verdadeiro que o processo de acúmulo de riqueza foi estimulado pelo processo vital. Na verdade o processo vital dos recursos humanos da indústria moderna, por meio do que Marx chamou de "trabalho alienado" e 
"trabalho desapossado"4, foi em grande medida sacrificado em benefício da apropriação; esse simulacro de "bem final" da abundância.

O escamoteamento da atividade da obra na modernidade, ou pelo menos do ideal de durabilidade que tradicionalmente presidiu a relação humana com os objetos mundanos, exigiu a ordenação da produção de objetos de uso segundo os princípios que presidem o processo de trabalho, isto é, a produção de objetos de consumo. E isso tanto em sentido técnico de ajuste do corpo humano ao ritmo das máquinas (para um aumento inusitado da produção), quanto em sentido organizacional de certa disposição força de trabalho implicada no conjunto das forças produtivas.

No aspecto relativo à nova alocação dessa força singularmente agenciada pela indústria moderna, o determinante, como mostra Arendt, é que a natureza do processo produtivo da obra tenha sido alterada por meio da introdução do "princípio de divisão do trabalho" nas linhas de produção do capitalismo industrial. Pois o critério de ordenação do trabalho é distinto do critério organizacional de especialização ou qualificação que caracteriza a obra, cujo operar é sempre orientado pelo produto final.

Um princípio geral de organização constitui a este respeito o único solo comum das atividades do trabalho e da fabricação. E este princípio não deriva da natureza mesma de tais atividades, mas antes do fato de que os homens podem coordenar suas ações, podem atuar em concerto. Razão porque, para Arendt, este princípio organizacional em sentido indeterminado deve sua origem à esfera estritamente política da vida, de acordo com a qual o homem não apenas é capaz de agir, como também de agir em concerto, isto é, de comum acordo com seus iguais.

Mas a diferença em nada secundária para a moderna disposição das forças produtivas está em que, em se tratando da obra, é o princípio de qualificação, fundamentalmente orientado pelo produto acabado da atividade em questão, que requer e articula em um conjunto as

\footnotetext{
4 Para Marx, a legitimidade da teoria do valor-trabalho, cujo mérito deve ser conferido a Adam Smith, consiste no fato por ele assinalado de que o valor do trabalho é derivado da luta hostil entre capitalista e operário. Assim, na realidade histórica do capitalismo, a taxa mais baixa da força de trabalho é o equivalente à quantia mínima capaz de garantir a subsistência elementar do trabalhador e de sua família, a fim de fazer com que ele (o trabalhador), esteja submetido à necessidade imperiosa de se manter neste trabalho e garantir concomitantemente a "perpetuação de sua raça". (MARX, 1993, p. 54)
} 
diferentes habilidades necessárias ao produto esperado. Enquanto que o princípio organizador da mera divisão do trabalho, na medida em que dispensa toda sorte de qualificação produtiva, mediante uma sistemática decomposição das funções qualificadas em múltiplas partes, supõe uma equivalência qualitativa, no sentido de um nivelamento por baixo, das atividades que antes eram tidas como singulares. De outra maneira o capitalismo industrial não poderia ter sido deflagrado por meio da mobilização de uma classe camponesa desapropriada e tecnicamente desqualificada.

Doravante, segmentadas em partes diminutas, estas atividades não exigem qualquer habilidade especial, como quando todo o processo produtivo da obra esteve exclusivamente confiado ao artesão. Na condição de força de trabalho, de recursos humanos inespecíficos, os indivíduos são totalmente intercambiáveis. A composição das forças produtivas da indústria moderna resulta da soma simples e meramente quantitativa das forças inespecíficas de trabalho, tal como elas derivam da sistemática dissolução da qualificação produtiva em partes simples. Este reagrupamento, que ao final do expediente de desintegração de habilidades especiais do processo produtivo disponibiliza apenas "força de trabalho" coletivizada (por meio da soma geral de suas frações), foi o resultado imediato do ajustamento do operar ao princípio organizacional típico da divisão do trabalho.

A divisão do trabalho supõe o fato incontestável de que unidos em prol de um interesse privado em comum, os homens podem (como exemplifica a organização familiar) proceder como se constituíssem um só indivíduo, uma unidade. Considerando que nas circunstâncias modernas de produção, ajustadas ao princípio de divisão do trabalho, os indivíduos se tornam intercambiáveis como em nenhuma outra situação, pode-se dizer que a unidade potencial da espécie humana, no nível biológico, foi assimilada para fins de produtividade. A mudança na natureza da obra submetida ao princípio de divisão do trabalho resulta do abandono do produto acabado em benefício da referência processual da atividade do trabalho, que a partir de então passou a contar com uma força coletiva e inesgotável.

A inesgotabilidade da força de trabalho coletivizada é o resultado da redução das especialidades produtivas ao mínimo denominador comum de qualificação (a execução mais 
simples com que o obra pôde se prestar à divisão), graças à qual a unidade da espécie tem a força global de trabalho potencialmente mobilizada para a produtividade moderna de bens de uso, do mesmo modo como os indivíduos estão naturalmente aptos a produzir, com a abundância da fertilidade natural de suas forças de trabalho, os bens destinados ao ciclo vital de seus organismos.

Nas modernas condições de divisão do trabalho, nas quais a obra é desintegrada em um processo interminável e cujo sujeito ativo é uma ilimitada força de trabalho coletivizada, e não uma força de trabalho individual limitada, "a inesgotabilidade dessa força de trabalho corresponde exatamente à não mortalidade da espécie, cujo processo vital como um todo também não é interrompido pelo nascimento e pela morte individuais dos seus membros" (ARENDT, 2010, p. 153). 0 aspecto complementar do quadro de uma "humanidade socializada", conforme indicamos acima, é a socialização pela qual a própria capacidade de acumular riqueza supera os limites da vida individual, tragando com isso as concepções tradicionais de propriedade e riqueza.

A riqueza que um dia foi considerada condição para o exercício da liberdade política, já há algum tempo é especialmente concebida como potencial de consumo em expansão, e neste sentido é uma obstinada evidência do caráter não mundano da propriedade. Mesmo que nas circunstâncias de divisão do trabalho a força individual tenha sido condicionada a epifenômeno da força coletiva de trabalho e o metabolismo com as coisas à condição de incremento da riqueza social, a capacidade humana de consumo se manteve adstrita aos limites naturais de antes. A solução ao problema criado pelo ideal de abundância aplicado às coisas duráveis consiste em tratar objetos de uso à maneira de bens de consumo, "de sorte que uma cadeira ou uma mesa sejam então consumidas tão rapidamente quanto um vestido, e um vestido se desgaste quase tão rapidamente quanto o alimento" (ARENDT, 2010, p. 154).

Neste caso, embora a obra não produza absolutamente objetos para o consumo, os produtos resultantes da fabricação assumem o aspecto de produtos do trabalho, pois pelas inovações técnicas e organizacionais do processo produtivo, favorecidas pelo ritmo industrial dos corpos ajustados às máquinas, a repetição e a interminabilidade imprimiram na obra as marcas 
inconfundíveis do trabalho. A repetibilidade interminável do processo produtivo da obra, operacionalmente equacionada ao trabalho, é assegurada pelo emparelhamento das necessidades recorrentes do processo de consumo a que as coisas, indiferentemente da durabilidade, estão submetidas. 0 que o equacionamento operacional da obra ao trabalho deflagra na modernidade é a exigência de fazer do consumo uma relação indiscriminada com o universo das coisas; um imperativo político e uma necessidade econômica. De sorte que a atual economia de consumo é a expressão e o último desdobramento desse processo.

A repetição infindável do processo produtivo é justamente o resultado do fato de que, mediante a abundância, tais coisas "perderam" o caráter mundano com que tradicionalmente se prestavam ao uso. 0 que significa que a extraordinária aceleração da taxa de uso apaga aos poucos a diferença objetiva entre uso e consumo, entre o trabalho e a obra, entre os objetos mundanos e os bens de curta duração que não permanecem no mundo o suficiente para fazerem parte dele.

Essa maneira moderna de produzir e lidar com as coisas termina por consolidar uma economia em cujos cômputos a durabilidade é o grande obstáculo a ser diariamente superado para viabilizar o processo acelerado e interminável de reposição. 0 desperdício, isto é, o modo artificial de consumir coisas duráveis ou de arrastá-las para o processo vital da espécie, é o fundamento e o imperativo de uma economia de consumo.

Em nossa necessidade de substituir cada vez mais depressa as coisas mundanas que nos rodeiam, já não podemos nos permitir usá-las, respeitar e preservar sua inerente durabilidade; temos de consumir, devorar, por assim dizer, nossas casas, nossa mobília, nossos carros, como se estes fossem as "coisas boas" da natureza que se deteriorariam inaproveitadas se não fossem arrastadas rapidamente para o ciclo interminável do metabolismo do homem com a natureza. É como se houvéssemos rompido à força as fronteiras distintivas que protegiam o mundo, o artifício humano, da natureza, tanto o processo biológico que prossegue dentro dele quanto os processos naturais cíclicos que o rodeiam, entregando-lhes e abandonando-lhes a sempre ameaçada estabilidade de um mundo humano. Os ideais do homo faber, fabricante do mundo, que são a permanência, a estabilidade e a durabilidade, foram sacrificados à abundância, o ideal do animal laborans. (ARENDT, 2010, p. 155-156).

O sentido último do triunfo moderno do trabalho é a emancipação histórica da mentalidade consumidora. Mas é verdade que o animal laborans, mudado de condição fundamental da vida humana em figura histórica na modernidade, não pode a rigor metabolizar ou se misturar 
aos objetos mundanos para que eles sejam equiparados a produtos de consumo. De todo modo, é igualmente verdadeiro que o descarte é o expediente com que as coisas são arrastadas de volta ao processo vital da natureza, de onde um dia foram arrancadas para servirem à fabricação.

O aspecto desolador da ruína precoce com que minamos a durabilidade das coisas é que, embora descartadas do mundo, a menos que sejam imediatamente destruídas, elas acabam por reter durante um certo tempo o critério objetivo de inclusão dentre as coisas mundanas. Isso porque o préstimo potencial retido nas coisas descartadas instaura aquela espécie de nãomundo, o amontoado de artigos desconectados de que Arendt falou em termos hipotéticos quando considerou o nonsense de um mundo objetivo de coisas na ausência de uma existência humana condicionada por elas ${ }^{5}$. Pois a verdade é que o não-mundo assim compreendido, a saber, como não condicionante da existência humana, é justamente o produto imediato, uma espécie de mundo-refugo paralelo e sempre crescente da economia do desperdício.

Nesse caso, as coisas que são precocemente descartadas e substituídas por essa "lógica da reposição precipitada" (LIPOVETSKY, 2009, p. 184) constituem, no fim das contas, a mais obstinada evidência de um mundo sem sentido, que no contexto de uma situação imaginária Arendt chamou de não-mundo. A despeito do absurdo, este não-mundo derivado da economia de consumo/desperdício é hoje tão real quanto o próprio mundo. Sua taxa de crescimento é diretamente proporcional ao desuso sistemático promovido por um novo tipo de indústria que opera em conjunto com a produção de coisas, a chamada "indústria de remoção do lixo" (BAUMAN, 2008, p. 127).

Uma economia do desperdício indica a partir de si mesma o ajuste do consumo à condição de imperativo econômico; de relação dominante e economicamente necessária com as coisas. Relação de acordo com a qual todas elas necessitam ser descartadas quase tão rapidamente quanto aparecem no mundo, para que a produção e o consumo, organizados segundo o

\footnotetext{
5 "A objetividade do mundo - seu caráter-de-objeto [object-character] ou seu caráter-de-coisa [thing-character] e a condição humana complementam-se uma à outra; por ser uma existência condicionada, a existência humana seria impossível sem coisas, e estas seriam um amontoado de artigos desconectados, um não-mundo, se não fossem os condicionantes da existência humana". (ARENDT, 2010, p. 11)
} 
princípio de um processo interminável de reposição acelerada (o princípio do trabalho), não chegue a uma estagnação ou a um colapso.

Ao representar hipoteticamente o vértice de uma sociedade de consumidores Arendt imaginou a condição de não mais vivermos em um mundo durável de coisas, mas apenas de sermos compelidos por um processo cujos ciclos envolvem indistintamente as coisas na mesma temporalidade curta que preside os bens naturais garantidores do processo vital. Apenas em semelhante situação, num "mundo" integralmente destinado a alimentar o metabolismo humano, um cenário de consolidação plena de automação do trabalho que nos liberasse integralmente para o consumo, seríamos, no sentido mais radical da expressão, uma sociedade de consumidores.

Em tais condições econômicas o mundo seria compulsoriamente envolvido em um negligente processo vital altamente intensificado e artificializado, no qual o ritmo do trabalho livre de esforço, isto é, inteiramente automatizado, elevaria ao limite o aspecto devorador com que o consumo mina a durabilidade das coisas mundanas. Em suma, o limite do imaginável de uma sociedade de consumidores que já incorporamos é a condição de sermos impelidos pela extrema expansão artificial do processo biológico em virtude do qual produziríamos e devoraríamos um "mundo" a cada novo dia.

\section{Referências}

ARENDT, H. A condição humana. 11 ed. Trad. R. Raposo. Rio de Janeiro: Forense Universitária, 2010.

ARENDT, H. A Dignidade da Política. Ensaios e conferências. Rio de Janeiro: Relume-Dumará, 2002.

ARENDT, H. A promessa da política. Rio de Janeiro: Difel, 2008.

ARENDT, H. Homens em tempos sombrios. Lisboa: Relógio D’água, 1991.

BAUMAN, Z. Em busca da política. Rio de Janeiro: Jorge Zahar Editor, 2000.

BAUMAN, Z. Globalização. As consequências humanas. Rio de Janeiro: Jorge Zahar Editor, 1999.

BAUMAN, Z. Vida a crédito. Rio de Janeiro: Jorge Zahar Editor, 2010.

BAUMAN, Z. Vidas desperdiçadas. Rio de Janeiro: Jorge Zahar Editor, 2004.

DUARTE, A. 0 pensamento à sombra de Ruptura: política e filosofia em Hannah Arendt. Rio de Janeiro: Paz e Terra, 2000. 
DUARTE, A. Vidas em risco. Crítica do presente em Heidegger, Arendt e Foucault. Rio de Janeiro: Forense Universitária, 2010.

JARDIM, E. A duas vozes. Hannah Arendt e Octavio Paz. Rio de Janeiro: Civilização Brasileira, 2007.

LIPOVETSKY, G. A cultura mundo. Resposta a uma sociedade desorientada. São Paulo: Companhia das Letras, 2011.

LIPOVETSKY, G. A era do efêmero. Ensaios sobre o individualismo contemporâneo. São Paulo: Manole, 2009.

LOCKE, J. Segundo tratado sobre o governo civil e outros escritos. Trad. M. Lopes e M. da Costa. Rio de Janeiro, Petrópolis: Editora Vozes: 2001.

MARX, K. A Questão Judaica. São Paulo, Centauro editora, 2005.

MARX, K. Manuscritos Econômico-Filosóficos. Lisboa, Edições Avante, 1993.

Recebido em: 05/12/2021

Aprovado em: 13/12/2021

\section{Cícero Josinaldo da Silva Oliveira}

Cícero Josinaldo da Silva Oliveira é professor nos cursos de Bacharelado e Licenciatura em Filosofia da UFG Campus Cidade de Goiás. Doutor em Filosofia pela Pontifícia Universidade Católica do Rio de Janeiro (PUCRio 2014), possui graduação (2006) e mestrado (2009) em Filosofia pela Universidade Federal de Goiás (UFG). Foi professor efetivo no Curso de Licenciatura em Filosofia do Centro de Formação de Professores da Universidade Federal do Recôncavo (CFP-UFRB) entre 2016 e 2019. Tem experiência nas áreas de Filosofia Política, Ética, Filosofia da Educação e Filosofia Geral. Desenvolveu atividades de ensino e pesquisa na Faculdade de Filosofia da Universidade Federal de Goiás (FAFIL UFG) pelo Programa Nacional de Pós-doutorado (PNPD-CAPES) entre os anos de 2014-2016. Coordena os projetos de extensão universitária "Vilaboa Cine Clube - Filosofia e Cinema" e "Filosofia Goiás - mídias digitais dos cursos de Bacharelado e Licenciatura em Filosofia da UFG Regional Goiás", com foco no "Canal de Podcasts Filosofia Goiás". Atualmente é chefe da Unidade Acadêmica Especial de Ciências Humanas (UAECH) da UFG Campus Goiás. 